\title{
EPISTEMOLOGIA, COMPLEXIDADE E MULTICULTURALISMO: DESAFIOS DE COMPREENSÃO PARA O DIREITO, NA SOCIEDADE CONTEMPORÂNEA
}

\author{
Géssica Pereira Siqueira Tauchert ${ }^{1}$ \\ Maicon Rodrigo Tauchert ${ }^{2}$
}

\section{Resumo:}

O presente artigo tem por objetivo abordar a compreensão da complexidade por meio de uma reflexão complexa, demonstrando a possibilidade de interpretarmos os instrumentos normativos norteadores dos cursos de Direito no Brasil ao adotar como ponto de partida, uma leitura epistemológica complexo-sistêmica. A metodologia de abordagem qualitativa, de método dialógico, em pesquisa teórica, com coleta de dados bibliográficos e análise de dados de conteúdo. Procura demonstrar a possibilidade de uma compreensão mais adequada para a concepção de desenvolvimento e estruturação da formação dos juristas brasileiros. Em um contexto contemporâneo de contingência, intersubjetivismo, auto-reprodução e conexão em rede, algumas características que dão forma a sociedade contemporânea e que desvelam por sua vez, novos desafios ao método científico e a racionalidade, nos impondo a necessidade de uma nova leitura ou até mesmo de criação de pressupostos de interpretação e compreensão da sociedade contemporânea.

Palavras-Chave: Ensino do Direito; Autopoiése; Pragmática-Sistêmica.

\section{INTRODUÇÃO}

O desenvolvimento do presente trabalho se faz importante em virtude da relevância e necessidade de aprimoramento das formas de compreendermos a sociedade contemporânea, sobretudo de possibilitarmos os caminhos para uma concepção científico-jurídica no Brasil. Partimos desde a demonstração da possibilidade de desenvolvimento de uma nova epistemologia de compreensão, da necessidade de adequada compreensão da complexidade ${ }^{3}$ e do multiculturalismo ${ }^{4}$, para que possamos desenvolver uma nova interpretação e compreensão da sociedade e da ciência do Direito. Utilizamos principalmente dois dos instrumentos normativos que estabelecem as diretrizes dos cursos de Direito no Brasil, os quais: a Portaria n ${ }^{\circ} 1.886$ do Ministério da Educação e Cultura, do ano de 1994 e a Resolução n 9 do Conselho Nacional de Educação/Câmara de Educação Superior, do ano de 2004. As principais questões a serem enfrentadas são: a demonstração de uma epistemologia complexa, a compreensão da complexidade pelo Direito; a compreensão do multiculturalismo pelo Direito e a necessidade

\footnotetext{
1 Acadêmica discente do 9 período de Direito da Faculdade Católica Dom Orione. Araguaia-TO. E-mail: gessicasiqueira@hotmail.com

${ }^{2}$ Especialista e Mestre em Direito. Pesquisador Docente com dedicação exclusiva e Coordenador do Núcleo de Estudos em Negociação, Mediação, Conciliação e Justiça Restaurativa da FACDO. Coordenador do Programa Justiça Comunitária Araguaína (reconhecido nacionalmente pelo Instituto Innovare).E-mail: maicon_rodrigo_tauchert@hotmail.com

${ }^{3}$ Por complexidade compreendemos: a forma de relação social que desafia os paradigmas disciplinares e estabelece comunicação interagente entre o uno e o múltiplo entre o local e o global. MORIN, Edgar, 2007, pág. 30.

${ }^{4}$ Mosaico étnico, onde diferentes expressões culturais interagem, inter-relacionando-se. BERTASO, João Martins, 2007, pág. 58.
} vol.07, nº2, Rio de Janeiro, 2014. pp 590-616 590 
de respostas adequadas em Direito, às exigências da sociedade contemporânea ${ }^{5}$. Por fim, a questão a ser respondida: é possível o desenvolvimento de uma nova epistemologia de interpretação e compreensão da sociedade e dos instrumentos normativos em vigor, indicando uma possível resposta às novas exigências sociais?

\section{EPISTEMOLOGIA DE COMPREENSÃO DO COMPLEXO}

Para que possibilitemos a compreensão das relações comunicacionais complexas, formadoras de sistemas e subsistemas hipercomplexos, é fundamental concebermos uma lógica diversa da lógica clássica Aristotélica, de estrutura bivalente, onde as proposições dão-se a partir da determinação absolutista de verdadeiro ou falso, estabelecendo assim, os critérios de validade e legitimidade de uma preposição. Dessa forma dá-se o desenvolvimento das lógicas clássicas e modais. Pois o desenvolvimento da sintaxe e sua compreensão deram-se historicamente e dá-se faticamente, em um primeiro momento, organizando-se a partir de regras, axiomas e vocábulos, a partir de seus significados únicos, definidos pelo critério de validação bivalente, verdadeiro-falso. Portanto, a sintaxe possui sentido universal, pretende objetividade, clareza e conformação de sentido. É a regra do sentido e do significado. Na sintática há a relação de coerência lógica bivalente entre os signos. Adequa-se a relação de conformação do significado com os demais signos que o contextualizam de forma positiva ou negativa, ou seja, verdadeiro ou falso. Constroem-se signos e significados a partir de sua adequação lógica ao sistema em que se pretende inseri-los.

Nesse sentido, compreensões a partir de Russel e Wittgenstein em suas fases do 'atomismo lógico', procuram demonstrar, para que fosse possível a consolidação de uma 'Teoria da Verdade', deveria ela estar baseada na condição de traduzir os fatos do mundo em uma linguagem clara, pois "o arranjo das palavras em uma proposição atômica verdadeira refletiria o arranjo das coisas simples do mundo"6. A partir da "Teoria da correspondência' dessa forma, a linguagem deve corresponder ao fato por ela descrito e sua conformação linguística, deve ser logicamente estruturada. Pois, a "interpretação da correspondência como um isomorfismo está intimamente relacionada tanto com a teoria sobre a estrutura última do mundo, quanto com o ideal de uma linguagem perfeitamente clara, teses características do atomismo lógico"7. Já para Austin, a teoria da correspondência deve ser baseada nas relações convencionais entre as palavras e o mundo, ou seja, os significados dos fatos do mundo devem ser estabelecidos a partir de sentenças compostas por signos convencionalmente aceitos pelo meio onde está sendo proferido, dessa forma, as convenções demonstrativas correlacionam o significado e o fato. É uma compreensão refinada, pois lembremos que a construção de significados parte de uma convenção sobre o significante e a possibilidade dele traduzir os fatos do mundo de forma mais 'fiel' possível.

\footnotetext{
${ }^{5}$ Sociedade interconectada em suas manifestações culturais, econômicas, políticas, sociais, religiosas e jurídicas. MORIN, Edgar, 2002, pág. 126.

${ }^{6}$ HAACK, 2002, p.134

${ }^{7}$ HAACK, 2002, p. 135
} 
Assim, a lei sob essa perspectiva, tem de ser válida a todos, pois é universal, clara, objetiva, conforma sentido e significado, é convencional e pretende ser um ideal de linguagem conformativa.

Em um segundo momento, dá-se o desenvolvimento da lógica polivalente, concebida por Lukasiewicz quando de sua demonstração da possibilidade de axiomatização da lógica. Dessa forma, lógicas polivalentes em seu ponto de partida são concebidas como a possibilidade de verdades polivalentes. Inaugurando a perspectiva semântica na compreensão da lógica. Assim, a semântica possibilita a relação de coerência lógica que ocorre entre os signos e o contexto axiologicamente designado, é possível compreendermos como a relação entre os signos e os significados articulam-se no contexto axiológico. Para Susan Haack, “...penso que está claro que uma lógica polivalente não precisa requerer a admissão de um ou mais valores de verdade extra além, de 'verdadeiro' e 'falso' e, de fato, de que ela nem mesmo requer a rejeição da bivalência” ${ }^{\text {. }}$. Dessa forma, a lógica polivalente autoriza a realização da lógica bivalente previamente. Em uma clara superação de paradigma, usa o antigo como possibilidade do novo paradigma.

Nesse nível de linguagem e de raciocínio lógico, Smiley usa a lógica trivalente desenvolvida por Bochvar, ao atribuir a uma 'fórmula bem-formada', um terceiro valor, indicando que ela não tem nenhum valor de verdade. Esse terceiro valor de verdade, pode ser compreendido como um novo valor derivado de uma variante epistemológica de 'verdadeiro' e 'falso'.

No entanto, devemos possibilitar a compreensão de uma lógica semântica baseada em uma 'Teoria da coerência', pois esse é seu pressuposto fundamental. E para que fosse possível viabilizar o desenvolvimento de uma reflexão lógica semântica é necessário pensar um 'critério de autorização' da verdade, para integrar o significado. Para Wittgenstein, em um primeiro momento, em sua obra Tractatus, a verdade está fundamentada na correspondência. Em Carnap e Schlick, desenvolvem sua compreensão em dois momentos; no primeiro momento para eles, os enunciados relatam a experiência perceptiva imediata, assim, correspondem aos fatos de forma incorrigivel. Consequentemente a verdade em relação a outros enunciados está preservada, pois derivam diretamente da relação lógica com os primeiros enunciados verdadeiros. Dessa forma possibilita-se a relação entre enunciados, rompendo com a lógica sintática. Em Neurath, o critério de verdade somente é possibilitado em uma relação entre as crenças, ou seja, a busca pela verdade dá-se no reajuste constante de nossas crenças. Bradley tem compreensão em comum com Neurath nesse momento, postulam o critério de verdade como 'sistema', pois necessita de consistência e de amplitude. Nesse momento, podemos vislumbrar a forma de operatividade fechada e cognição aberta da 'Teoria sistêmica'. Assim, em Rescher há o desenvolvimento de uma epistemologia coerentista, a coerência como o próprio critério de verdade. Porém, nesse sentido se faz necessário à definição de um 'subconjunto maximal consistente', ou seja, um a priorie um imperativo categórico, para que os fatos novos

\footnotetext{
${ }^{8}$ HAACK, 2002, p. 280
} 
sejam validados logicamente através da linguística semântica, o que Quine chama de 'definição semântica da verdade’. Percebe-se dessa forma, que a estruturação de uma lógica correspondencial a partir da sintática é paradigma anterior e necessário à estruturação de uma lógica coerencial a partir da semântica, pois para viabilização desse paradigma, é necessário que aquele esteja estruturado anteriormente.

No terceiro momento, dá-se o desenvolvimento de uma lógica baseada na pragmática, onde pensadores como Peirce, James e Dewey combinam elementos de coerência com elementos de correspondência. Na compreensão pragmatista o significado dos enunciados dá-se por sua referência com as consequências práticas em sua aplicação. Em James, compreende-se que não há diferença que não faça diferença. Em Peirce, a verdade é o fim da investigação, demonstrada através do método científico, é a única verdade que pode levar ao consenso. Assim, a crença é uma disposição para a ação "e a dúvida como a interrupção de tal disposição por uma resistência por parte da experiência"".

Dessa forma, compreende-se que

[...] a verdade é a opinião na qual o método científico vai eventualmente se assentar, e uma vez que o método científico é condicionado pela realidade, a verdade é a correspondência com a realidade. Segue-se também que a verdade é satisfatória para a crença no sentido de que ela é estável, livre da perturbação da dúvida ${ }^{10}$.

Portanto, a adaptação dos preceitos lógicos, dá-se no momento de sua relação com novas experiências, de forma a preservar os preceitos fundamentais do antigo paradigma na restauração de sua consistência, confirmando sua veracidade na experiência.

No quarto e último momento, concebe-se a possibilidade da lógica autopoiética, baseada nas teorias da 'correspondência', 'coerência' e 'pragmática' da lógica, no paradigma sintático, semântico e pragmático da linguagem, correspondendo-o com o paradigma sistêmico e com a Teoria da Complexidade.

Na perspectiva da teoria da correspondência lógica, de categoria sintática da linguagem, a tradução do fato através da linguagem, em organização correspondencial, deve ser verossímil e a estruturação linguística do texto, deverá ser lógica e sintaticamente estruturada. Na perspectiva da teoria da coerência lógica, de categoria semântica de linguagem, a tradução do fato através da linguagem, em organização de correspondência e de coerência, dá-se na verossimilhança sintaticamente estruturada e em sua relação com a axiomatização na experiência, em uma organização sintática do texto, deve ele inserir-se coerentemente no contexto em que é proferido. Na perspectiva da teoria pragmática da lógica, de categoria pragmática da linguagem, a tradução do fato através da linguagem, em organização de correspondência, coerência e experiência prática de aplicação, dá-se na verossimilhança sintaticamente estruturada, em sua relação com a axiomatização da experiência e na

\footnotetext{
${ }^{9}$ HAACK, 2002, p. 140

${ }^{10}$ HAACK, 2002, p. 141
} 
consequência prática de sua aplicação, em um texto organizado sintaticamente, inserido coerentemente no contexto onde exsurge, confirmando-se em sua aplicação, na experiência.

Dessa forma, concebemos o Direito como linguagem logicamente estruturada em um processo de construção de definições por unidades, a norma jurídica. Que em sua unidade, está inserida em um contexto e deverá ser aplicada. Portanto, compreender o Direito como linguagem, que o significado de seu ser, é dado correspondentemente na sintática, coerentemente na semântica, confirmado praticamente na pragmática, inserido no contexto social complexo de relação, através da ação comunicativa na sociedade, compreendemos que a 'linguagem Direito', é ser-em, conformadora do ser-no-mundoe constituidora do modo-de-ser-no-mundo, enquanto existencial normativo.

Ao trazermos as matrizes do Direito para uma reflexão articulada com as compreensões a partir da lógica e do paradigma da linguagem, compreendemos a estrutura a forma de compreensão epistemológica do Direito. Para tanto, a matriz analítica de Kelsen, é teoria sintática, baseada em uma lógica de correspondência, de cunho bivalente, onde o critério de validade é dado a partir da preposição de verdadeiro ou falso. A matriz hermenêutica de Hart e Dworkin é teoria semântica, baseada em uma lógica de coerência e também de correspondência, de cunho polivalente, seu critério de validade é dado a partir de seu reconhecimento a partir de uma norma secundária que estabeleça o sistema jurídico e em sua justificação axiológica no contexto. A matriz pragmáticosistêmica de Luhmann, articula a sintaxe e a semântica sob o olhar sistêmico, para consequências na aplicação práticas, seu critério de validade é dado a partir de seu sistema cognitivo aberto, ou seja, sua informação é externa ao Direito e de seu sistema fechado de operatividade, onde somente o Direito pode dizer o que é Direito, tendo como base suas decisões anteriores.

Ao concebermos a complexidade como uma relação de heterogeneidade onde múltiplos fatores constituem o tecido social, demonstrando-nos a possibilidade de relação entre o uno e o múltiplo. É ela a própria relação constituinte dos fenômenos sociais. A partir dos emaranhados relacionais no tecido social, constituídos historicamente na tradição, em um processo constante de construção, desconstrução e reconstrução cada vez mais complexo, há a urgente necessidade de viabilizarmos uma compreensão que seja condição de possibilidade para o Direito, enquanto existencial normativo, na sociedade contemporânea.

Dessa forma ao assumirmos que a ciência, como domínio cognitivo constituído através da aplicação do critério de validação das explicações científicas, não toma a verdade em sentido transcendental, mas com a explicação da experiência humana no âmbito das próprias experiências humanas, nesse processo construtivodestrutivo-reconstrutivo, muitas questões desaparecem ou perdem inteiramente seu caráter, e novas compreensões são possíveis e necessárias. Assim, as possibilidades da compreensão sistêmica podem ser ampliadas, se a concebermos não como traduções de verdades essenciais, mas como possibilidade interpretativa 
da linguagem, dos fenômenos sociais e jurídicos, de sua ação e de como esses fenômenos não apenas reagem aos estímulos externos da realidade, mas, em seus próprios signos a constituem.

Portanto, ao conceber a possibilidade de compreendermos a sociedade e o Direito a partir da interrelação entre correspondência, coerência e pragmática, na lógica; da sintática, semântica e pragmática, na linguagem; da complexidade social e da teoria sistêmica, tendo claro que não há possibilidade de desenvolver compreensão na complexidade, baseando-nos em pressupostos não complexos, pois estaríamos tentando explicar o intersubjetivismo a partir da racionalidade, por exemplo. Podemos afirmar que a adoção primeira, para viabilidade desse paradigma, é de uma epistemologia complexa, capaz de interagir e de se renovar constantemente, baseada em uma lógica autopoiética.

\section{LÓGICA AUTOPOIÉTICA}

A condição de possibilidade de compreensão da complexidade passa antes pela forma de como vamos desenvolver nosso pensamento. Essa forma, não mais se identifica com as formas clássicas de compreensão do mundo, porém, para que viabilizemos o desenvolvimento da compreensão na complexidade, é necessário sabermos como será estruturada essa compreensão.

Nesse sentido, iniciamos a questão com reflexão sobre a 'ógica difusa' proposta por Zadeh, que pode ser compreendida como resultado da superação da lógica bivalente para a lógica polivalente, porém, para a caracterização da lógica difusa, a polivalência é não-enumerável. A lógica não-enumeravelmente polivalente, permite "graus de pertinência a conjuntos denotados por predicados da linguagem-objeto, e a passagem para muitos valores de verdade contavelmente difusos como um resultado de se tratar como vago o próprio predicado metalinguístico "verdadeiro ${ }^{11}$. Da lógica difusa, resulta que seus valores de verdade, não estão enclausurados em operações de negação, conjunção, disjunção e implicação. Portanto, a lógica difusa articula valores de verdade difusos. Nesse momento evidenciamos a forma de sociedade complexa e multicultural e suas infinitas possibilidades. Onde cada cultura evidencia de forma peculiar a sua tradição e suas formas de compreensão de mundo. No processo de inter-relação dessa cultura com as demais, produzimos a complexidade e a hipercomplexidade. Dessa forma, tende-se a articularmos diferentes valores, que ao se inter-relacionarem, difundem-se no meio social e complexo.

Para tanto, referenciamos a 'lógica paraconsistente', a qual se fundamenta em sistemas dedutivos inconsistentes os quais admitem teses contraditórias e sobretudo, a contradição, de forma a dispor que nem todas as fórmulas lógicas encontram-se em seu sistema. Criada pelo lógico brasileiro Newton C. A. da Costa a partir da

\footnotetext{
${ }^{11}$ HAACK, 2002, p. 224
} 
década de 50, quando aprofunda sua pesquisa no sentido de desenvolver sistemas lógicos que pudessem envolver contradições, motivado por questões de natureza tanto filosóficas quanto matemáticas.

Assim, ao pretendermos compreender a complexidade, deveremos fornecer elementos complexos, como instrumentos a serem articulados no desenvolvimento da compreensão. Dessa forma, a lógica autopoiética pretende estruturar a epistemologia da complexidade. Pode ser compreendida como o sistema que está simultaneamente ligada ao passado, presente e futuro, é aberta e fechada, possui repetição e diferença, equacionando em seu interior esse paradoxo, o qual será articulado para filtrar as informações referentes ao seu próprio sistema, estando assim, intimamente ligada a um critério de repetição e diferença simultânea.

Dependendo a partir de qual sistema ou subsistema pretendemos compreender o mundo, partimos de sua lógica pluralista local, que "relativiza as ideias extra-sistemáticas de validade e verdade lógica, e, portanto, a ideia da correção de um sistema lógico, a uma área específica do discurso. Um argumento não é simplesmente válido, e ponto final!" ${ }^{\prime 2}$. Mas ele é válido sempre em. Considerando a contingencialidade do ambiente como elemento essencial para a produção da lógica autopoiética, neste caso o ambiente necessita de informação, para que no complexo de desordem possa desenvolver a ordem auto-organizada. A relação do observador não mais se verifica entre sujeito-objeto, e sim, entre sujeito-sujeito onde ele se auto referencia. A lógica deixa de ser um sistema independente e matematificado, e a sociedade por consequência deixa de ser a simples soma das interações ou ações presentes, validadas como verdadeiras ou falsas, para ser vista como uma ordem maior, uma inter-relação entre valores de verdade difusos, determinada pela diferença entre sistema e ambiente. Assim, compreendendo a sociedade como policontextural ${ }^{13}$, diversos sistemas lógicos interagem de forma complementar, sem preponderância de nenhum.

A lógica autopoiética articulará a informação entre sistema e ambiente em uma recursão operativamente fechada e cognitivamente aberta, baseada em elementos fundamentais que estruturam e caracterizam seu sistema, como a polivalência não-enumerada, na lógica difusa ou os direitos humanos e fundamentais, no princípio da dignidade da pessoa humana e no principio do meio ambiente sadio e equilibrado, quando se pensa em Direito por exemplo, articulados com valores de verdade difusos, evidenciados pelo ambiente, na inter-relação.

A partir da lógica autopoiética e da teoria dos sistemas, caracteriza-se o Direito ou qualquer outro subsistema, como autopoiético, estruturando-se de forma aberta cognitivamente e fechada operativamente. Assumindo função binária no sentido de validar o que é, e o que não é informação para seu próprio subsistema, como por exemplo, somente o Direito pode dizer o que é, e o que não é Direito. Portanto, determina-se pelo próprio subsistema em um processo de autodeterminação positiva, o que se insere e o que se exclui de sua

\footnotetext{
${ }^{12}$ HAACK, 2002, p. 291

${ }^{13}$ ROCHA, 2003
} 
recursividade, a partir da policontextura do ambiente em validação auto-referencial, baseada em uma lógica que se auto-reproduz continuamente com sua inter-relação com o ambiente e sua contingencialidade. Justificando dessa forma, internamente sua validade, tornando desnecessário demonstrar o elemento que fundamente em instância apriorística, sua validade. Sendo assim, sua validade é confirmada no processo de inter-relação com o ambiente.

Portanto, os critérios de validação, na lógica autopoiética, estão em continua renovação, possibilitada pelas relações e inter-relações entre ambiente, sistema e subsistemas, onde os critérios de validade exsurgem na medida em que, através do processo de comunicação, proporcione seu acoplamento estrutural. A 'Teoria da verdade’ nesse momento é a possibilidade de conjugação sintática, semântica e pragmático-sistêmica e seus critérios de validação, a partir disso, são determinados pelas relações comunicativas. Conformando assim, uma epistemologia capaz de possibilitar a compreensão e o desenvolvimento das ciências sociais e aplicadas, na complexidade.

\section{COMPLEXIDADE E MULTICULTURALISMO: UMA REFLEXÃO NECESSÁRIA PARA O DIREITO}

O desenvolvimento de uma compreensão da complexidade e do multiculturalismo é possibilitada a partir da reflexão autopoiética ${ }^{14}$, como explanado no item anterior. Quando falamos em epistemologia ${ }^{15}$, temos de ter claro que a (re)fundação de um novo paradigma de compreensão, passa pela superação/aprimoramento do paradigma de relação sujeito-objeto, para/pelo o paradigma de relação sujeito-sujeito; a estruturação dessa epistemologia dar-se-á na possibilidade de articulação, por meio da autopoiése, das formas de compreensão de mundo, ou seja, das teorias da verdade em seu sistema de validação e produção de conhecimento como anteriormente exposto, através da comunicação entre as possibilidades lógicas e naturalmente de suas impossibilidades lógicas, tendo como uma das bases à teoria autopoiética; entendemos que a partir de uma lógica que se auto reproduz ${ }^{16}$, instrumentalizando-a com o paradigma da linguagem ${ }^{17}$, possibilitaremos dessa maneira, a criação de uma epistemologia da complexidade, ou seja, a forma de desenvolver os pressupostos de compreensão do complexo.

Quando compreendemos a complexidade, desvelamos as infinitas possibilidades de relações e interrelações entre o sistema e os subsistemas, entre o sujeito e o objeto e fundamentalmente entre o sujeito e o sujeito; desvelamos as possibilidades do uno e do múltiplo ao mesmo tempo; da abertura cognitiva e do fechamento

\footnotetext{
${ }^{14}$ Do grego auto"próprio", poiesis" criação", o que se autoproduz.

${ }^{15}$ Do grego episteme "ciência", logia "estudo de", o estudo da ciência.

${ }^{16}$ TAUCHERT, Maicon Rodrigo. 2011.

${ }^{17}$ Sintática, semântica e pragmática.
} 
operativo para a produção do conhecimento de cada subsistema; desvelamos sua complexificação e hipercomplexificação, dados em uma ação comunicativa constante e auto reprodutora.

No multiculturalismo desvelamos o mosaico de possibilidades culturais produzidas a partir de sua interrelação, possibilitada pela linguagem; desvelamos que ao compreendermos o outro como altero, como sujeito, possibilitamos a relação intercultural; desvelamos que a relação intercultural está baseada em validações e valores difusos e auto reprodutores; que a intersubjetividade na alteridade é a possibilidade do reconhecimento.

Ao compreendermos o Direito racionalmente (baseado em pressupostos metodológicos pré-definidos que atuam como regras imutáveis), estabelecemos aprioristicamente as inviabilidades de compreendermos a sociedade contemporânea, pois, o fluxo relacional do sujeito tanto local, quanto global, está para além do sistema jurídico cogente. Esse sistema de raízes estatais modernas, não possui mecanismos e instrumentos eficientes e eficazes de corresponder juridicamente às relações e inter-relações do sujeito, em um contexto atual de conexão local e global em rede. Ao tentarmos interpretar a sociedade contemporânea com preposições estanques e de burocrática atualização, nos enclausuramos em pressupostos inadequados, inviabilizantes de qualquer compreensão da multiculturalidade e complexidade. Portanto, procura-se proporcionar anteriormente, uma compreensão da sociedade baseada em sua própria complexidade, para então proporcionarmos ao operador do Direito, as possibilidades substanciais de tornar-se intérprete do Direito, justificando assim, a natureza desse artigo.

Dessa forma, devemos possibilitar uma reflexão "que considere não só a organização e a vida das ideias em sistemas, teorias e doutrinas, não só a lógica, mas também [...]”18 a epistemologia.

Portanto, o

[...] problema-chave da comunicação e da compreensão entre as idéias, as teorias, as visões do mundo, numa palavra, entre indivíduos e entre culturas. Temos que considerar a grande dificuldade que as teorias têm em comunicar umas com as outras 19 .

Neste ponto, a possibilidade dessa comunicação é dada no momento em que desenvolvermos a inter e transdisciplinaridade entre nossas teorias (ciências), nesse caso o Direito, para que seja possível articulá-lo com outras teorias (ciências) que ligadas em rede, formam a teoria do conhecimento complexo. Articulamos a compreensão do Direito, a partir da compreensão da própria sociedade, ou seja, ao Direito cabe corresponder sintaticamente em seu texto normativo à sociedade a qual é produto, cabe ser coerente semanticamente em sua aplicação na realidade social à qual é destinado e transformativo da realidade pragmaticamente, na forma da lógica autopoiética.

O Direito pensado a partir desse ponto é instrumento de compreensão da sociedade, através de sua abertura cognitiva (observação inter e transdisciplinar) e de seu fechamento operativo (somente no direito produzem-se as normas jurídicas), ou seja, o Direito (intérprete do Direito e da sociedade) 'observa' a sociedade,

\footnotetext{
${ }^{18}$ MORIN, 2002, p. 30.

${ }^{19}$ MORIN, 2002, p. 31.
} 
interpreta-a e a compreende, trazendo para dentro de seu sistema de produção principiológica e normativa, todos os elementos sociais que exigem respaldo do ordenamento jurídico, transformando-os em resposta principiológica e normativa, correspondentes, coerentes e transformativos daquelas exigências.

Ao compreendermos esse contexto demonstrado, a partir do paradigma da linguagem e da teoria da verdade, construídos pela lógica autopoiética, seremos capazes de produzir um Direito que corresponda com a realidade, ou seja, que preveja no ordenamento jurídico, as regras a serem seguidas de forma clara e precisa; que seja coerente em suas respostas aos anseios sociais, ou seja, um Direito contextualizado com sua sociedade; seja pragmático em sua atuação, transformativo da realidade; tenha clareza sintática em seu texto, adequação semântica em relação a seu contexto e transformativo pragmático em sua aplicação; analítico em sua estruturação, o que lhe proporcionará fácil compreensão, hermenêutico em sua contextualização, o que the proporcionará precisão ao contexto em que é proferido e pragmático-sistêmico em sua compreensão e aplicação, para ser transformativo da realidade e que sempre possua resposta para aos anseios da sociedade. É um Direito que através de sua aplicação, transforma e equilibra, promove e concretiza, reconhece e efetiva, tendo como seus elementos fundamentais a essência da existência do Estado Democrático de Direito. Sendo assim, para que possamos viabilizar essa interpretação e compreensão da sociedade; produção, aplicação e atualização do Direito, é necessário determinarmos um ponto de partida de nossa reflexão e Direito, nesse caso em específico: o princípio da dignidade da pessoa humana e o princípio do meio ambiente sadio e equilibrado.

Dessa maneira, a produção normativa e sua aplicação, terão como fim último, a promoção da dignidade da pessoa humana e a proteção do meio ambiente. Evidentemente que a normatividade abrange as mais diversas áreas do Direito, p.ex. constitucional, econômico, penal, civil, tributário, trabalhista, internacional, dentre outros; assim, nos inúmeros subsistemas do Direito, àqueles elementos basilares devem ser respeitados, preservados e atualizados. Por exemplo: quando o Direito Econômico, mesmo que de matiz neoliberal, é aplicado, não deverá ser à custa da dignidade do ser humano nem do meio ambiente; o mesmo deve ocorrer sempre que da produção e aplicação de todos os subsistemas do Direito. Assim sendo, mesmo que o Direito assuma todas as formas normativas imagináveis e viabilize todas as condições (econômicas, trabalhistas, comerciais, para citar alguns) necessárias para sua aplicação, será sempre promovedor de seus princípios basilares.

Destarte, precisamos ter conhecimento que o desenvolvimento histórico do direito e de seu ensino no Brasil, desde seu início é usado como instrumento de força das elites oligárquicas que detém o poder público e a gestão dos negócios do Estado brasileiro, usando-o como instrumento de exploração e supressão das classes sociais menos favorecidas economicamente. Também, devemos ter claro que o constitucionalismo brasileiro, ao longo de sua formação, chancelava o domínio da burguesia oligárquica em detrimento do povo brasileiro, salvo em raríssimas exceções. Que a história política do Brasil, é marcadamente conturbada e infectada seriamente pela 
corrupção, pelo compadrio e pelo favorecimento pessoal. Que a evolução dos direitos humanos no Brasil se dá casuisticamente, pois, para a classe detentora do poder público e econômico existe direitos humanos para protegêlos, já para a classe explorada (a grande massa do povo brasileiro) existe a pena, o direito penal. A relação desses fatores durante a formação do Direito brasileiro e de sua concepção jurídica, influencia de tal maneira que conformaram sentido de um Direito brasileiro alheio à realidade social.

Podemos então, compreender que a leitura analítica ultra positivista praticada pelos operadores do Direito brasileiro, desde sua fundação, demonstra uma espécie de enclausuramento em seu próprio método objetificante, de cunho fundamentalista e opressivo. Evidencia-se assim, os processos de ensino e repetição desse Direito, seriamente comprometidos e inapropriados para o contexto da sociedade brasileira contemporânea. Ao refletirmos essa sociedade a partir da teoria sistêmica, onde as relações entre os subsistemas produzem outros subsistemas cada vez mais complexos e dinâmicos, em um processo de autoprodução. Aliamos à teoria sistêmica com a teoria da complexidade, onde tudo se relaciona interinfluenciando-se e ao multiculturalismo, onde as expressões culturais e a diferença devem ser respeitadas e preservadas. Demonstra-se a necessidade da criação de uma nova epistemologia do Direito brasileiro, a epistemologia complexa. Fundamentada no paradigma da linguagem (sintática, semântica e pragmática) e na teoria da verdade (correspondência, coerência e pragmática) possibilitadas na teoria da complexidade e na teoria sistêmica. Pretende-se oferecer uma reflexão, a partir dos pressupostos legais que hoje nos são possíveis (Resolução CNE/CES n 9, de 29 de setembro de 2004 do Conselho Nacional de Educação e Câmara de Educação Superior. Que institui as diretrizes curriculares nacionais do curso de graduação em direito e dá outras providências), demonstrando outra possibilidade reflexivo-aplicativa desses instrumentos normativos baseados na presente proposta epistemológica.

\section{DIRETRIZES CURRICULARES DOS CURSOS DE DIREITO NO BRASIL SOB UMA PERSPECTIVA COMPLEXA E MULTICULTURAL}

Ao pensarmos em normatividade, poderemos adotar no mínimo duas perspectivas diretivas dos currículos dos Cursos de Direito no Brasil. Integradas a um sistema nacional de política de Educação Superior, a Resolução 9 do CNE/CES do ano de 2004 e a Portaria 1886 do MEC do ano de 1994, são importantes elementos normativos referenciais a serem instrumentalizados sob uma perspectiva complexa e multicultural. $\mathrm{Na}$ pretensão de possibilitarmos uma nova leitura desses instrumentos normativos consolidados, e viabilizarmos uma formação de intérpretes da sociedade e do Direito, capazes de traduzir a sociedade para o Direito e a partir de sua aplicação, possibilitar as respostas adequadas aos novos paradigmas exurgentes.

\section{PORTARIA NÚMERO 1.886 DE 1994, QUE FIXA AS DIRETRIZES CURRICULARES E O CONTEÚDO MÍNIMO DO CURSO JURÍDICO}


A Portaria do Ministério da Educação, de número 1886 de 30 de dezembro de 1994, publicada no Diário Oficial da União em 4 de janeiro de 1995, normatiza o conteúdo curricular mínimo dos cursos de Direito no Brasil.

Além da exigência de uma estrutura mínima, como por exemplo, em seus artigos $1^{\circ} \mathrm{e} 2^{\circ}$, de "o mínimo de 3.300 horas de atividades, cuja integralização se fará em pelo menos cinco e no máximo oito anos letivos", onde o “[...] curso noturno, que observará o mesmo padrão de desempenho e qualidade do curso no período diurno...”, a previsão de um acervo bibliográfico mínimo (artigo 5o), a obrigatoriedade de apresentação e defesa de trabalho monográfico para a conclusão do curso (artigo 9o), o estágio obrigatório e o mínimo de seu decurso (artigo 10), fixa também as exigências mínimas de formação subjetiva do acadêmico de Direito.

Para tanto,

Art. $3^{\circ} \mathrm{O}$ curso jurídico desenvolverá atividades de ensino, pesquisa e extensão, interligadas e obrigatórias, segundo programação e distribuição aprovadas pela própria Instituição de Ensino Superior, de forma a atender às necessidades de formação fundamental, sóciopolítica, técnico-jurídica e prática do bacharel em direito.

Estabelece a obrigatoriedade de interligação entre as atividades elementares de ensino, pesquisa e extensão, para o desenvolvimento de uma "formação fundamental", que possibilite ao acadêmico as condições mínimas de reflexão, compreensão e aplicação da norma no contexto social e político que está inserido, a Portaria, está nos autorizando uma reflexão sob a perspectiva complexo-sistêmica no multiculturalismo, que forneçam os elementos básicos para a leitura dessa norma, na sociedade contemporânea. Pois, para que haja a "formação fundamental”, em sentido sócio-político, se faz necessário dispor de meios adequados de compreensão da sociedade e de seu contexto político, ou seja, devemos ter claro que a complexidade, a contingência e o multiculturalismo, características fundamentais da sociedade contemporânea e a forma sistêmica de como isso produz a própria sociedade e sua humanidade. Ao considerarmos as principais características da sociedade contemporânea, nos é permitido integrar esses elementos aos pressupostos de compreensão do próprio Direito e da formação dos juristas brasileiros.

Portanto,

Art. 4 Independentemente do regime acadêmico que adotar o curso (seriado, créditos ou outro), serão destinados cinco a dez por cento de carga horária total para atividades complementares ajustadas entre o aluno e a direção ou coordenação do curso, incluindo pesquisa, extensão, seminários, simpósios, congressos, conferências, monitoria, iniciação cientifica e disciplinas não previstas no currículo pleno.

A exigência principal desse artigo são as "atividades complementares", compreende-se como uma forma de proporcionar ao acadêmico, possibilidades de integração entre pesquisa, extensão e outras variadas formas de inter e transdisciplinaridade entre os conteúdos, no sentido de disponibilizar ao acadêmico, possibilidade de novas reflexões e compreensões a partir da integração de várias perspectivas. No entanto, essas atividades necessitam de uma abordagem diferenciada, no sentido de esclarecer ao acadêmico em formação, a necessidade de 
desenvolvimento de suas habilidades e competências para a articulação entre várias perspectivas, a mais adequada ao seu contexto. Dessa forma, essas informações e sua apreensão dar-se-ão dialogicamente, ou seja, ao ter contato cognitivo com variadas possibilidades, o acadêmico as elabora e as assimila a partir de seu ambiente social, fundamentalmente com a possibilidade de aplicação prática transformativa desse meio, através dos instrumentos que the são proporcionados. Compreendemos ser essa uma das primordiais habilidades e competências a serem estimuladas e desenvolvidas no acadêmico, quando do cumprimento dessa Portaria.

A Portaria também se preocupa em estabelecer os conteúdos mínimos que deverão ser disponibilizados para a formação do acadêmico,

Art. $6^{\circ} \mathrm{O}$ conteúdo mínimo do curso jurídico, além do estágio, compreenderá as seguintes matérias, que podem estar contidas em uma ou mais disciplinas do currículo pleno de cada curso.

I - Fundamentais: Introdução ao Direito, Filosofia geral e jurídica, Ética Geral e Profissional, Sociologia (geral e jurídica), Economia e Ciência Política (com Teoria do Estado);

II - Profissionalizante: Direito Constitucional, Direito Civil, Direito Administrativo, Direito Tributário, Direito Penal, Direito Processual Civil, Direito Econômico, Direito do Trabalho, Direito Comercial e Direito Internacional.

Parágrafo único. As demais matérias e novos direitos serão incluídos nas disciplinas a se desdobrar o currículo pleno de cada curso, de acordo com suas peculiaridades e com observância de interdisciplinaridade.

Assim, ao estabelecer os conteúdos mínimos, compreende-se a preocupação com a estrutura mínima do curso em seus conteúdos mais elementares, evidentemente. Porém, a forma que essa estrutura, em que os conteúdos mínimos, as "demais disciplinas" e "novos direitos" deverão ser articulados e ministrados, está estabelecida no final do parágrafo único, que é a interdisciplinaridade. Portanto, o primeiro momento de produção de conhecimento complexo para uma adequada formação de intérpretes através dos cursos de Direito. Pois, somente quando do desenvolvimento de uma formação interdisciplinar, será possibilitada ao acadêmico a habilidade de articulação entre todos os conteúdos conformadores de sua formação e a competência de uma adequada aplicação desse processo de integração. O segundo momento de produção do conhecimento complexo, no entanto, é a transdiciplinaridade, a qual é possibilidade de superação dos limites de cada paradigma disciplinar, promovendo a comunicação e inter-relação entre eles.

No entanto, desde a Portaria número 1886 de 1994 estão expressas as preocupações com a formação do bacharel em Direito. No sentido de que esta proporcione subsídios intelectuais para o desenvolvimento de habilidades e competências, que lhe capacitem um intérprete de nossa sociedade multicultural e complexa. 


\section{RESOLUÇÃO NÚMERO 9 DE 2004, DO CONSELHO NACIONAL DE EDUCAÇÃO E CÂMARA DE EDUCAÇÃO SUPERIOR.}

A Resolução do CNE/CES número 9 de 2004, institui as diretrizes curriculares dos cursos de graduação em Direito no Brasil, pretendendo estabelecer os critérios básicos de estruturação dos cursos e da formação do bacharel em Direito. Sendo assim um referencial normativo, concretizado por uma construção normativa através do Parecer CES/CNE 55/2004 de 2004, pelo Parecer CNE/CES 211, fruto de uma longa reflexão de especialistas da área é marco referencial para reflexão. Sendo assim, extrairemos os principais aspectos dessa resolução e os refletiremos a partir da perspectiva apresentada por esse artigo.

O Projeto Pedagógico dos Cursos de Direito, tendo como referência essa resolução, terá de abranger o perfil do formando, suas competências e habilidades, os conteúdos curriculares do curso, o estágio, as atividades complementares, o sistema de avaliação, o trabalho de conclusão de curso, a oferta de vagas disponíveis, a duração do curso, tendo claro que, no Projeto Político Pedagógico, além de obrigatoriamente constar as diretrizes da resolução, poderão constar outras, tendo como base, o local do curso e suas características sociais, culturais, políticas e econômicas, para que o curso justifique sua importância para a região em que esteja localizado, e consequentemente, ao contexto sociocultural que esteja inserido.

A resolução impõe normativamente que

Art. 3. O curso de graduação em Direito deverá assegurar, no perfil do graduando, sólida formação geral, humanística e axiológica, capacidade de análise, domínio de conceitos e da terminologia jurídica, adequada argumentação, interpretação e valorização dos fenômenos jurídicos e sociais, aliada a uma postura reflexiva e de visão crítica que fomente a capacidade e a aptidão para a aprendizagem autônoma e dinâmica, indispensável ao exercício da Ciência do Direito, da prestação da justiça e do desenvolvimento da cidadania.

Dessa forma, estabelece o eixo transversal de seu conteúdo. Ao compreendermos o artigo $3^{\circ}$, temos claro o reconhecimento das incapacidades do modelo analítico, objetivista-positivista, demonstrando-nos os elementos básicos a serem articulados. Que constituem a capacidade do graduando em pensar apropriadamente a sociedade e o Direito. Ao refletirmos sobre as partes e sobre a totalidade dessa norma, nos está claro a lucidez da proposta, no que se refere à formação de não mais operadores do Direito e sim de intérpretes da sociedade e do Direito.

Portanto,

Art. 4. O curso de graduação em Direito deverá possibilitar a formação profissional que revele, pelo menos, as seguintes habilidades e competências:

I - leitura, compreensão e elaboração de textos, atos e documentos jurídicos ou normativos, com a devida utilização das normas técnico-jurídicas;

II - interpretação e aplicação do Direito;

III - pesquisa e utilização da legislação, da jurisprudência, da doutrina e de outras fontes do Direito;

IV - adequada atuação técnico-jurídica, em diferentes instâncias, administrativas ou judiciais, com a devida utilização de processos, atos e procedimentos;

V - correta utilização da terminologia jurídica ou da Ciência do Direito; 
VI - utilização de raciocínio jurídico, de argumentação, de persuasão e de reflexão crítica;

VII - julgamento e tomada de decisões; e,

VIII - domínio de tecnologias e métodos para permanente compreensão e aplicação do Direito.

No artigo $4^{\circ}$ demonstram-se os instrumentos básicos que o intérprete deverá ter desenvolvido em sua formação, para que exerça de forma mais elementar sua função na atuação. No sentido de desenvolver habilidades e competências para compreensão, articulação e aplicação dos requisitos exigidos por esse artigo.

No,

Art. 5 O curso de graduação em Direito deverá contemplar, em seu Projeto Pedagógico e em sua Organização Curricular, conteúdos e atividades que atendam aos seguintes eixos interligados de formação:

I - Eixo de Formação Fundamental, tem por objetivo integrar o estudante no campo, estabelecendo as relações do Direito com outras áreas do saber, abrangendo dentre outros, estudos que envolvam conteúdos essenciais sobre Antropologia, Ciência Política, Economia, Ética, Filosofia, História, Psicologia e Sociologia.

II - Eixo de Formação Profissional, abrangendo, além do enfoque dogmático, o conhecimento e a aplicação, observadas as peculiaridades dos diversos ramos do Direito, de qualquer natureza, estudados sistematicamente e contextualizados segundo a evolução da Ciência do Direito e sua aplicação às mudanças sociais, econômicas, políticas e culturais do Brasil e suas relações internacionais, incluindo-se necessariamente, dentre outros condizentes com o projeto pedagógico, conteúdos essenciais sobre Direito Constitucional, Direito Administrativo, Direito Tributário, Direito Penal, Direito Civil, Direito Empresarial, Direito do Trabalho, Direito Internacional e Direito Processual; e

III - Eixo de Formação Prática, objetiva a integração entre a prática e os conteúdos teóricos desenvolvidos nos demais Eixos, especialmente nas atividades relacionadas com o Estágio Curricular Supervisionado, Trabalho de Curso e Atividades Complementares.

No artigo 5o, estão dispostos os eixos de formação do curso. No inciso I, o Eixo de Formação Fundamental demonstra a clara preocupação com a inter-relação do acadêmico com campos de conhecimento que possibilitem a compreensão, antes, da sociedade. Nesse aspecto, podemos falar que o Direito sob o aspecto normativo, deverá estar cognitivamente aberto na comunicação com outros subsistemas, os quais lhe fornecerão posicionamentos a partir de diferentes observações, para um mesmo horizonte, a compreensão da sociedade e a normatividade. Para tanto, o uso da lógica autopoiética ${ }^{20}$ é necessário, pois ao confrontar-se com valores diferentes, inter-relacionando-os com seus próprios, produzirá novos valores, os quais difundir-se-ão em novas inter-relações em um infinito processo de auto reprodução.

No inciso II, o Eixo de Formação Profissional demonstra a preocupação de ter seu núcleo de operação bem definido, ou seja, sua estrutura dogmática compreendida na forma sintática correspondente. A possibilidade de desenvolver conhecimento com esses elementos (aqui estão inclusos os diversos campos de conhecimento, como impõe o inciso I) somente tem utilidade quando for contextualizado pela semântica na coerência e aplicado na pragmática, ou seja, quando for correspondente, coerente e tiver aplicabilidade. Sua abertura às 'mudanças' só será possível, se estiver aberto cognitivamente e sofrer influência através de suas inter-relações com o contexto

${ }^{20}$ TAUCHERT, Maicon Rodrigo. 2011. 
complexo da sociedade. Sua produção como Direito, só será possível se em sua operação interna, usar desses elementos externos para atualização e desenvolvimento, através do processo legislativo, jurisprudência e doutrina, por exemplo.

No inciso III, o Eixo de Formação Prática é essencialmente pragmático, seu principal objetivo é a 'integração' entre a sintática linguística e correspondência lógica, com a semântica linguística e coerência lógica, sobretudo na pragmática linguística e pragmática lógica, em sua aplicação. Essa 'integração’ é perfeitamente possível quando pensamos sistemicamente, produzindo assim, a epistemologia complexa. Ao produzirmos essa complexidade, estamos munidos com os pressupostos condizentes para compreendermos a complexidade e a multiculturalidade, onde esses pressupostos legais serão aplicados.

Sendo assim, como anteriormente disposto, ao Direito não é possibilitada a compreensão da sociedade complexa partindo de pressupostos estritamente racionalistas, fundados na analítica objetivista. Ao possibilitarmos a complexificação dos pressupostos de conhecimento do Direito, possibilitamos também sua compreensão do complexo e consequentemente a possibilidade dele como instrumento normativo fornecer as respostas adequadas às exigências complexas, contingenciais e multiculturais, características fundamentais da sociedade contemporânea.

A partir da compreensão dessas exigências, sob uma perspectiva complexo-sistêmica, proporciona-se ao acadêmico uma formação que the integre como estudioso da sociedade e do Direito, tornando-se efetivamente um intérprete do Direito para a sociedade contemporânea.

Para tanto, no processo de desenvolvimento das Políticas Pedagógicas dos Cursos de Direito, há autonomia para adequação de seu projeto para atender essas exigências. $O$ desenvolvimento e a promoção da interdisciplinaridade são um dos instrumentos eficazes para iniciarmos essa concepção, pois dessa maneira é fornecida ao acadêmico a possibilidade de inter-relação entre as disciplinas que compõe sua formação. Pensemos: sem a efetivação da interdisciplinaridade, ao acadêmico é fornecido um curso fragmentado em disciplinas desconexas e independentes umas das outras; recebe ele, informações para formação de seu conhecimento, de forma disciplinarmente objetivista. Porém, ao concluir seu curso, pretenderá aplicar suas informações em sua vida profissional, e nesse momento, haverá um imensurável choque de realidades, pois se depara com uma sociedade complexa, com relações intersubjetivas, difusas, instáveis, que se modificam incessantemente e que produzem novas exigências a cada nova inter-relação. Percebe agora, que seu método, não lhe fornece os pressupostos reflexivos e metodológicos adequados a proporcionar-lhe respostas satisfatórias a esse 'novo contexto'. Pois está munido somente com instrumentos analíticos e objetivados.

Portanto, a Resolução 9 de 2004, exige a interdisciplinaridade, que é o primeiro momento de produção de conhecimento complexo, através de um protótipo da 'religação dos saberes' de Edgar Morin. Sendo assim, a 
interdisciplinaridadeé a possibilidade de inter-relação através da comunicação entre as disciplinas de todo o curso, a ligação entre a reflexão sociológica, filosófica e política com o direito civil de família, a ligação entre a reflexão econômica, política e sociológica com o direito do consumidor, por exemplo, e entre todas as disciplinas. Somente assim, viabiliza-se a produção de conhecimento do Direito, ao contrário, temos somente um sistema tautológico, fechado em si mesmo, baseado em capacidade de repetição pura e simples.

Para proporcionarmos esse próximo passo da educação e compreensão, citamos o princípio de Pascal,

[...] sendo todas as coisas causadas e causadoras, ajudadas ou ajudantes, mediatas e imediatas, e sustentando-se todas por um elo natural e insensível que une as mais distantes e as mais diferentes, considero ser impossível conhecer as partes sem conhecer o todo, tampouco conhecer o todo sem conhecer particularmente as parte ${ }^{21}$.

O desenvolvimento de aptidões gerais da mente humana possibilita o desenvolvimento de competências particularizadas, ou seja, o estímulo ou o despertar da inteligência geral nos proporciona a capacidade de compreendermos e inter-relacionarmos o uno e múltiplo. A interdisciplinaridade é o primeiro momento para a percepção do global, e consequentemente, a condição para o desenvolvimento de habilidades e competências particulares.

No entanto, o não desenvolvimento de uma percepção global, conduz ao não desenvolvimento da responsabilidade e de sua identidade como jurista, pois vemos como nossa única função, tarefas especializadas desconexas do todo, bem como o não desenvolvimento da solidariedade, pois, a cada um não estão possibilitados o sentimento e a percepção dos vínculos intersubjetivos, possibilitados na dimensão do todo. O desenvolvimento dessas capacidades é fundamental para que se promova a "sólida formação geral, humanística e axiológica" que a resolução impõe. O segundo momento de produção do conhecimento complexo, é a transdiciplinaridade, a qual é possibilidade de superarmos os limites de cada paradigma disciplinar, promovendo a comunicação e interrelação entre eles, o que é essencial para essa proposta. A transdiciplinaridade é a constante transmutação disciplinar, ou seja, para que ultrapassemos os limites paradigmáticos impostos por cada especialidade, se faz necessário sua inter-relação com o todo e com as demais especialidades, essa inter-relação é perfeitamente concebida no pensamento complexo-sistêmico.

Portanto, a cada nova inter-relação na interdisciplinaridade, devemos possibilitar a abertura cognitiva e promover a intercomunicação nessa inter-relação, que produzirá novas percepções e novas possibilidades, aprimorando a forma de como compreendemos o mundo. Assim, o princípio hologramático ${ }^{22}$, da teoria da complexidade é possibilitado. Será possível perceber em cada particularização, o holograma do todo e em cada totalização a representação das partes, através da comunicação proporcionada pela linguagem, desenvolvidas sistemicamente. A transdiciplinaridade é a possibilidade de uma compreensão complexa, a qual é o fundamento

\footnotetext{
${ }^{21}$ MORIN, op. Cit. PASCAL, 2007, p. 37.

${ }^{22}$ MORIN e MOIGNE, 2000, p. 213.
} 
para compreensão do mundo contemporâneo, e consequentemente a possibilidade de produzirmos conhecimento complexo.

A educação neste novo cenário ampliou de forma considerável a proposta do Relatório da UNESCO sobre a "Educação para o Século XXI" de setembro de 1996, recomendando essencialmente o desenvolvimento humano, compreendido como a evolução da "capacidade de raciocinar e imaginar, da capacidade de discernir, do sentido das responsabilidades". Evidentemente faz com que (re)valorizemos a dimensão ética e cultural da educação e, portanto, a proporcionar efetivamente ao acadêmico, os meios de compreender a si mesmo, de compreender o outro na sua especificidade e de compreender o mundo. Pois, é nos bancos escolares e acadêmicos o primeiro passo para a estruturação do paradigma social, político, econômico, jurídico e estatal do século XXI.

Atualmente em um currículo baseado no desenvolvimento de competências e habilidades conforme a resolução, compreendemos que a noção de competência refere-se à capacidade de compreender uma determinada situação e reagir razoavelmente a partir dela, ou seja, na relação com o meio, surgem ações novas e complexas, as quais exigem tratamento adequado pelo sujeito pensante. Competência está relacionada ao saber, exigindo o desenvolvimento de habilidades. Que pode ser compreendida como aptidão ou destreza para desenvolver algo, ou seja, capacidade de desenvolver potencialmente sua intelectualidade, sua criatividade, sua aptidão geral e também específica.

Dessa forma, a resolução do CNE/CES número 9 de 2004, compreende e instrumentaliza de forma elementar, as exigências contemporâneas e as mudanças urgentes e necessárias no ensino do Direito no Brasil, na formação de intérpretes do Direito para sociedades complexas e multiculturais. Porém, para que isso aconteça se faz necessária uma interpretação e compreensão igualmente complexos.

\section{DA POSSIBILIDADE A EFETIVIDADE DE FORMAÇÃO DE INTÉRPRETES PARA SOCIEDADES MULTICULTURAIS E COMPLEXAS}

A formação de intérpretes para sociedades multiculturais e complexas exige o desenvolvimento de pressupostos de compreensão também complexos. Para que isso aconteça, é necessário (re)fundarmos os pressupostos e os preceitos em que nos baseamos para a compreensão do mundo, os quais, a inter e a transdisciplinaridade. Por consequência, o Direito, como ciência social aplicada, sofre também a necessidade dessa transição paradigmática. Portanto, seus pressupostos de compreensão e desenvolvimento, deverão ser fundamentalmente sociais aplicados e não objetivos matematificados, característica dos pressupostos das ciências exatas. 
A possibilidade é o primeiro passo a ser constituído para a efetividade de formação de intérpretes da sociedade e do Direito, capazes de compreendê-la e desenvolvê-la. Os instrumentos dessa possibilidade, já são dados doutrinaria e legalmente, como exposto no decorrer desse artigo. O próximo passo é a instrumentalização da efetividade. O grande paradoxo 'impeditivo' dessa efetividade é certamente a forma como compreendemos as possibilidades, ou seja, essas são dadas pontual e isoladamente, e dessa maneira são possibilidades inócuas, na medida em que não existe a compreensão para sua inter-relação e intercomunicação. As mudanças pretendidas deverão ser mudanças em rede, ou seja, devem estar interligadas comunicativamente auto-interrelacionando-se em um constante processo de autoprodução, endo-exo referenciado.

Devemos ter claro como nossos conhecimentos são estabelecidos, ou seja, racionalista, disciplinar, analítica e objetivamente. Outrora demonstrado, que partimos de pressupostos lógicos de cunho dedutivo. Que a 'teoria da verdade' em filosofia, é constituída fundamentalmente, a partir da validação de pressupostos verdadeirofalsos, ou seja, tudo o que é determinado falso, é afastado da formação da compreensão e do conhecimento e tudo o que é determinado verdadeiro é acoplado a essa formação de nossa compreensão. Que se dá de forma estritamente matemática, em relação lógica de forma binária entre verdadeiro-falso. Assim, a diferença/o diferente, como não é lógico-dedutivamente compreendido, é rechaçado. E passa a não existir para a ciência que o analisou. Dessa maneira, somente um sistema fechado em si mesmo, poderá dizer o que é, e o que não é verdade, o que formará e o que não formará sua compreensão e seu conhecimento, logo, sua ciência.

O Direito como todas as ciências ocidentais, desenvolveu-se a partir dessa noção de verdade/validação. Porém, quando tentamos usar esse paradigma de racionalidade para compreendermos o mundo contemporâneo, mesmo em ciências exatas, temos a hiperespecialização e consequentemente a dificuldade de comunicação entre essas áreas. Pois uma importante característica da hiperespecialização é seu extremo isolamento em relação às outras especializações. Quando pensamos em ciências sociais aplicadas, nos é dificultada sobremaneira a reflexão, pois ao tentarmos usar esses pressupostos isolados/enclausurantes, nos deparamos com a impossibilidade de compreensão da sociedade complexa e multicultural contemporânea. A grande questão hodierna são as interrelações em rede em um constante processo de autoprodução de complexidade e hipercomplexidade, onde tudo se relaciona com tudo e nessas relações produzem cada vez mais, novos subsistemas. Para que pretendamos compreender a sociedade e a partir dela, refletir nossas ciências sociais aplicadas é essencial viabilizarmos uma 'teoria da verdade' (epistemologia) complexa. Nesse momento, pretendemos fazer uso da lógica autopoiética. A lógica, por ser pressuposto do conhecimento, requer (re)formulação desde o princípio.

A lógica autopoiética proporcionará a compreensão para conhecimento complexo, na medida em que se auto-renova constantemente, está ela em constante processo de inter-relação com os fenômenos sociais e autoproduzindo-se a partir deles, proporcionado dessa maneira, a possibilidade de compreensão e 
desenvolvimento do conhecimento na complexidade. Fazendo uso do paradigma da linguagem, na perspectiva anteriormente exposta, ou seja, sob a perspectiva analítica, semântica e pragmática, sob o olhar autopoiético, viabilizamos o desenvolvimento da comunicação entre os subsistemas sociais complexos em uma 'teoria da verdade' (epistemologia) complexa.

O Direito pode perfeitamente ser refletido a partir da teoria do conhecimento, onde também (re)fundase seus pressupostos de compreensão. Dessa maneira, suas três matrizes epistemológicas, a matriz analítica, a matriz hermenêutica e a matriz pragmático-sistêmica, devem se inter-relacionar sistemicamente, no paradigma da linguagem ao mesmo tempo na sintática, semântica e pragmática, compreendidos assim, a partir de uma lógica autopoiética, na complexidade.

Ao usarmos instrumentos normativos como a Portaria 1886 de 1994 do MEC e a Resolução 9 de 2004 do CNE/CES, viabiliza-se um novo paradigma de implantação e estruturação dos cursos de Direito. Com a Portaria e a Resolução refletidas e aplicadas na perspectiva desse artigo, certamente teremos cursos de Direito em consonância com a multiculturalidade e complexidade da sociedade contemporânea. Capazes de fornecer ao acadêmico, uma sólida formação e desenvolver sua capacidade de compreensão do Direito em relação à sociedade.

\section{CONSIDERAÇÕES FINAIS}

Temos na interpretação e compreensão da sociedade e do Direito e por consequência em seu ensino, o maior desafio enfrentado desde sua fundação, onde seu desenvolvimento nos possibilitou chegarmos a essas reflexões e a partir disso propormos possibilidades de um novo paradigma epistemológico complexo a ser desenvolvido desde a constituição dos cursos de Direito e da formação dos juristas brasileiros.

A possível resposta a indagação anteriormente feita é: é possível uma nova forma de interpretação da sociedade e dos instrumentos normativos desenvolvidos pelo interprete do Direito e da sociedade. Porem, para tanto, se faz necessária a reformulação da forma de como produzimos nosso conhecimento e por consequência dos pressupostos de interpretação e compreensão do Direito e da sociedade, para que as respostas que produziremos sejam correspondentes à realidade, sejam claras, precisas e bem definidas; coerentes ao contexto onde estarão sendo proferidas, representando de maneira eficaz sua realidade social; e pragmáticas sistêmicas, para que proporcionem transformação da realidade e se auto produzam a cada nova inter-relação exurgente, estando sempre atualizadas com as mudanças sociais.

Como pesquisadores, docentes, discentes e todos os intérpretes do Direito, teremos de refletir essa nova proposta, para que proporcionemos as respostas que a sociedade espera de todos nós. Que respondamos 
adequadamente à complexidade, contingência, intersubjetividade e a conexão das relações sociais em forma de rede, que definem a sociedade contemporânea e desafiam o Direito e sua reflexão.

\title{
EPISTEMOLOGY, COMPLEXITY AND MULTICULTURALISM: CHALLENGES FOR THE UNDERSTANDING OF LAW IN CONTEMPORANY SOCIETY.
}

\begin{abstract}
:
This article aims to address the understanding of complexity through a complex reflection, demonstrating the possibility of interpreting the guiding normative instruments of the law school in Brazil, is adopted as a point of departure a pragmatic-systemic epistemological reading. The methodology of qualitative approach, dialogical method in theoretical research, collecting bibliographic data and analysis of content. Seeks to demonstrate the possibility of a more adequate understanding for designing developing and structuring the training of Brazilian jurists. In a contemporary context contingency, inter subjectivity, auto playback and networking, some characteristics that shape contemporary society, in turn unveil new challenges to scientific method and rationality, and imposes the need for a new reading or even creating assumptions for interpretation and understanding of contemporary society.
\end{abstract}

Keywords: Law Teaching; Autopoiesis; Pragmatic-Systemic.

\section{REFERÊNCIAS}

BERTASO, João Martins. Cidadania e demandas de igual dignidade: dimensão de reconhecimento na diversidade cultural. In. OLIVEIRA JUNIOR, José Alcebíades de (org.). Faces do Multiculturalismo: teoria, política, direito. Santo Ângelo: EDIURI, 2007.p. 57-83.

BRASIL, Parecer do Conselho Nacional de Educação 0055 de 18 de fevereiro de 2004. In. Diário da União de 18 de fevereiro de 2004.

BRASIL, Parecer do Conselho Nacional de Educação 211 de 18 de fevereiro de 2004. In. Diário da União de 18 de fevereiro de 2004.

BRASIL, Portaria Ministerial 1.886 de 30 de dezembro de 2004. In: Diário da União de 4 de janeiro de 1995.

BRASIL, Resolução 09 de 29 de setembro de 2004 do Conselho Nacional de Educação/CES. In: Diário Oficial da União de $1^{\circ}$ de outubro de 2004.

BRASIL. Constituição da República Federativa do Brasil. Promulgada em 5 de outubro de 1988. 40a edição. São Paulo: Saraiva: 2007.

BRASIL. Decreto n. 5.773 de 9 de maio de 2006. Dispõe sobre o exercício das funções de regulação, supervisão e avaliação de instituições de educação superior e cursos superiores de graduação e sequenciais no sistema federal de ensino. Disponível em: http://www.planalto.gov.br/ccivil_03/_Ato2004-2006/2006/Decreto/D5773.htm. Acesso em 09 de fevereiro de 2014. 
BRASIL. Lei n. 9.394, de 20 de dezembro de 1996. Estabelece as diretrizes e bases da educação nacional. Diário Oficial da União, Brasília, v. 248, p. 27833-27841, 23 dez. 1996. Seção 1.

HAACK, Susan. Filosofia das Lógicas. São Paulo: Unesp. 2002.

LUHMANN, Niklas. El derecho como sistema social. No hay derecho, ano V, n. 1157, ago. / oct. 1994.

KHUN, Thomas Samuel. A Estrutura das Revoluções Científicas. São Paulo. Perspectiva. 2008.

MORIN, Edgar. A Religação dos saberes. O desafio do século XXI. 3. ed., Rio de Janeiro: Bertrand Brasil. 2002.

MORIN, Edgar. O Problema Epistemológico da Complexidade. Lisboa: Biblioteca Universitária. Mem Martins. Portugal. 2002.

MORIN, Edgar. Os Sete Saberes necessários à Educação do Futuro. 2a edição. Brasília: Cortez. Unesco. Distrito Federal. 2000.

MORIN, Edgar. Introdução ao Pensamento Complexo. 3a edição. Porto Alegre: Sulina. RS.

MORIN, Edgar. O Problema Epistemológico da Complexidade. Lisboa: Biblioteca Universitária. Mem Martins. Portugal. 2002.

MORIN, Edgar; LE MOIGNE, Jean-Louis. A Inteligência da Complexidade. São Paulo: Petrópolis, 2000.

OLIVEIRA, Manfredo A. de. Reviravolta Linguístico-Pragmática na Filosofia Contemporânea. 3aa edição. São Paulo - SP. Edições Loyola. 2006.

PARSONS, Talcott. O Sistema das sociedades modernas. Traduzido por Dante Moreira Leite. São Paulo: Pioneira, 1974.

PENA-VEGA, Alfredo; NASCIMENTO, Elimar Pinheiro do. Org. O Pensar Complexo. Edgar Morin e a Crise da Modernidade. $3^{a}$ edição. Rio de Janeiro: Garamond. RJ. 1999.

ROCHA, Leonel Severo. Org. Paradoxos da Auto-Observação. Percursos da teoria jurídica contemporânea. Curitiba.JM, 1997.

ROCHA, Leonel Severo. SCHWARTZ, Germano. CLAM, Jean. Introdução à teoria do sistema autopoiético do Direito. Porto Alegre. Livraria do Advogado. 2005.

ROCHA, Leonel Severo. Epistemologia Jurídica e Democracia. 2a edição. São Leopoldo: Unisinos. 2005.

SANTOS, André Leonardo Copetti; MORAIS, José Luis Bolzan de. O Ensino Jurídico e a Formação do Bacharel em Direito. Diretrizes político pedagógicas do curso de Direito da Unisinos. Porto Alegre. Livraria do Advogado. 2007.

SAUSSURE, Ferdinand de. Curso de linguística geral. 24a ed. Traduzido por Antonio Chelini, José Paulo Paes e Izidoro Blikstein. São Paulo: Cultrix, 2002. 
TAUCHERT, Maicon Rodrigo. Sintaxe, Semântica e Pragmática-sistêmica. Compreensão e Desenvolvimento de uma Lógica Autopoiética a partir do Paradigma da Linguagem. Disponível em: http:/ / www.uj.novaprolink.com.br. Acesso em 09 de fevereiro de 2014.

UNESCO, Organização das Nações Unidas para a educação, a ciência e a cultura. Relatório para a UNESCO da Comissão Internacional sobre educação para o século XXI. Disponível em: http://unesdoc.unesco.org/images/0010/001095/109590por.pdf. Acesso em 9 de fevereiro de 2014.

WARAT, Luis Alberto. Epistemologia e Ensino do Direito: o sonho acabou. Florianópolis. Fundação Boiteux. 2005.

ZADEH, L. A. BELLMAN, R. E. Local and fuzzy logic, em Modern Uses of Multiple-Value Logic. Utah State University. 1977.

Trabalho enviado em 21 de abril de 2014.

Aceito em 22 de julho de 2014. 